\title{
Vesical stone management by percutaneous cystolitholapexy versus open vesicolithotomy among children.
}

1. MBBS, FCPS (Urology) Assistant Professor Urology and Kidney Transplantation Pir Abdul Qadir Shah Institute of Medical Sciences Gambat.

2. MBBS, MS (Urology)

Senior Registrar Urology and Kidney Transplantation

Pir Abdul Qadir Shah Institute of Medical Sciences Gambat.

3. MBBS, FCPS

Assistant Professor Pediatric Surgery

Pir Abdul Qadir Shah Institute of

Medical Sciences Gambat.

Correspondence Address:

Dr. Muhammad Shahid Bhatti Department of Urology and Kidney

Transplantation

Pir Abdul Qadir Shah Institute of Medical Sciences Gambat.

bhatti.shahid340@gmail.com

Article received on: 08/02/2021

Accepted for publication: $16 / 04 / 2021$

\begin{abstract}
Muhammad Shahid Bhatti ${ }^{1}$, Abdul Qayoom Khuhro², Illahi Bux Brohi ${ }^{3}$
\end{abstract}
ABSTRACT... Objective: To compare outcomes, safety and complications of vesical stone management among children by open vesicolithotomy versus percutaneous cystolitholapaxy. Study Design: Cross Sectional study. Setting: Department of Urology and Kidney Transplantation Pir Abdul Qadir Institute of Medical Sciences Gambat. Period: July 2020 to December 2020. Material \& Methods: Children with vesical stone, having age 1-12 years and fulfilling inclusion criteria were selected for this study. Total 50 cases were selected using nonprobability consecutive sampling technique. Patients were divided into two groups Group-A and Group-B on the basis of given treatment each group containing 25 cases. Patients in Group-A were underwent open vesicolithotomy and those in group-B were underwent percutaneous cystolitholapexy. Procedure was done under general anesthesia. Alken metallic dilators were used for the dilatation of tract. Adult nephroscope with 24Fr sheath was used. Postoperative outcomes of both methods were compared with each other. Pneumatic fragmentation was used to break stones $>1.5 \mathrm{~cm}$ in size. Results: Total 50 cases were studied, 25 cases in each group-A and group-B. Stone size was $1-3 \mathrm{~cm}$ in both groups. Age range of the patients was $1-12$ years with mean age of $4.25 \pm 1.4$ years. Mean hospital stay was 2.6 days in group-A and 1.3 days in group-B. Mean requirement of analgesia (ketorolac) was $30.2 \mathrm{mg}$ in group-A and $14.8 \mathrm{mg}$ in group-B. Most common postoperative complication was fever observed in $28 \%$ cases in group-A and hematuria observed in $24 \%$ cases in group-B. Conclusion: Percutaneous cystolitholapexy is a minimal invasive procedure suitable among children with high success rate and minimum complications like postoperative fever, hematuria, urinary leakage and pain.

Key words: Open Vesicolithotomy, Percutaneous Cystolitholapexy, Vesicolithotomy, Vesical Stone.

Article Citation: Bhatti MS, Khuhro AQ, Brohi IB. Vesical stone management by percutaneous cystolitholapexy versus open vesicolithotomy among children. Professional Med J 2021; 28(12):1742-1746.

https://doi.org/10.29309/TPMJ/2021.28.12.6419

\section{INTRODUCTION}

Urolithiasis is a very common disease in Asian countries. ${ }^{1}$ Among children vesicolithiasis is very common. Bladder stones are crystals formed by protein and minerals in urine which precipitate and accumulate in bladder ultimately converting to a solid stone. ${ }^{2}$ Vesicolithiasis account for $5 \%$ of total urinary tract stones. Vesical stone is also called bladder calculai or cystoliths. ${ }^{3}$ In developed countries its incidence has been reduced but in underdeveloped and developing countries like Africa, South and East Asia and Middle East it is still a very common problem. In Pakistan its incidence is $31 \% .{ }^{4}$ Its incidence is more among boys than girls and especially high incidence in age above 50 years. ${ }^{3,4}$ Peak incidence among children has been noted at the age of 5 years. According to a report about 1-19.1\% population suffer from urolithiasis. ${ }^{4}$ Epidemiological data revealed that stone formation among children is due to nutritional deficiency of phosphates due to replacement of milk products by carbohydrates leading to the formation of insoluble salts and high excretion of ammonia. ${ }^{5}$ Other causes include excessive use of oxalate rich foods and low animal proteins. Among girls due to short urethra mostly stone debris is excreted easily and does not retain in bladder so that's why incidence of vesicolithiasis is low. In males stone debris is retained in bladder and accumulates to form vesical stone. ${ }^{6}$ Growth of stone depends on deposition and reabsorption of insoluble salts 
which continue for years. ${ }^{7}$ Common presenting complaints among patients with vesical stone are lower abdominal pain, burning micturition, urinary interruption and rubbing and pulling of penis, frequency, dysuria and urinary retention. ${ }^{8}$ Usually vesical stone is removed by open vesicolithotomy but with the advancement in medical field minimal invasive procedures are now being used for vesical stone removal. ${ }^{9}$ These procedures include transurethral stone fragmentation using holmium laser or intra-corporeal cystolithotripsy, percutaneous cystolithotripsy and vesicolitholapexy. These all methods are cost effective with low morbidity, minimum complications and short hospital stay required. ${ }^{10}$ This study has been conducted so that we may document our experience.

\section{MATERIAL \& METHODS}

This is a cross sectional study conducted in urology and kidney transplantation Pir Abdul Qadir Institute of Medical Sciences Gambat. Study was completed in six months duration from July to December 2020. Sample size was calculated using WHO sample size calculator. Patients' selection was done using non-probability consecutive sampling technique.

Patients were divided into two groups depending on the treatment given. In group-A patients underwent open vesicolithotomy and in group-B percutaneous cystolitholapaxy was done for vesical stone removal. Age range of patients was 1-10 years. Male and female both types of patients were included. Patients not operated previously and having stone size $<3 \mathrm{~cm}$ were included in this study. Postoperative outcomes were evaluated in terms of hematuria, requirement of drain placement, postoperative pain, analgesia requirement and mean duration of hospital stay. Informed consent was taken from all the study patients in written form. Ethical approval was taken from ethical review board of the study institution (AMC/PGMI/LGH/Article/Research No/00-175-20). Cystoscopy was done in all patients. Stones in urethra were pused back into bladder to examine properly. Nephroscope with 24Fr sheath was used for PCCL (percutaneous cystolithotomy). PCCL was done in modified lithotomy position after filling urinary bladder fully with $8 f r$ feeding tube. 18 gauge spinal needle was inserted into bladder via suprapubic route, guide wire passed, serial dilatation done, nephroscope with 24Fr sheath passed into bladder and stone examination was done. Stone removed with triple jaws stone grasper. Among the patients undergoing open vesicolithotomy nelton drain placed in perivesical area for 24 hours and foleys catheter retained for 03 days and among the patients undergoing PCVL only Wound closed and foleys catheter retained for 3 days. Ketorolac $10 \mathrm{mg}$ was given I/V for pain relief. Data was documented and analyzed using SPSS-21. Chi square test was applied. P-value $<0.05$ was considered statistical significant. Percentage and frequencies were calculated for qualitative variables. Means and standard deviation were calculated for quantitative variables using student t-test. Results were depicted using tables and graphs.

\section{RESULTS}

Total 50 cases were included in this study. Two groups were made each comprising on 25 cases. In group-A 15(60\%) were male and 10(40\%) were female cases, mean stone size was $2.8 \mathrm{~cm}$, mean age was $4.8 \pm 2.6$ years. In group-B $17(68 \%)$ were male and $08(32 \%)$ were female cases, mean stone size was $1.9 \mathrm{~cm}$ and mean age of the patients was $3.7 \pm 1.4$ years.

In group-A fever was observed in $07(28 \%)$ cases and hematuria in 06(24\%) cases, while in group-B fever was observed in 02(08\%) cases and hematuria in $03(12 \%)$ cases. Foleys catheter was retained for 03 days and nelton drain for 24 hours in group-A, and in group-B foleys cystostomy tube was retained for 24 hours. Ketorolac was given as analgesia 10-40mg mean dose $30.2 \pm$ $5.38 \mathrm{mg}$ in group-A and $10-20 \mathrm{mg}$ mean dose $14.8 \pm 9.65 \mathrm{mg}$ in group-B.

Hospital stay was 2-3 days with mean stay of 2.6 \pm 0.65 days in group-A, and $1-2$ days with mean stay of $1.3 \pm 0.52$ days in group-B. Duration of surgery was $60-80$ minutes with mean duration of $70.5 \pm 13.24$ minutes in group-A, and 3050 minutes with mean duration of $40.6 \pm 8.86$ minutes. 


\begin{tabular}{|l|c|c|}
\hline \multicolumn{1}{|c|}{ Patients Characteristics } & Group-A (\%=N/50) & Group-B (\%=N/50) \\
\hline \multicolumn{1}{|c|}{ Age (years) } \\
\hline $1-3$ & $02(04 \%)$ & $03(06 \%)$ \\
\hline $4-6$ & $05(10 \%)$ & $07(14 \%)$ \\
\hline $7-9$ & $10(20 \%)$ & $06(12 \%)$ \\
\hline $10-12$ & $08(16 \%)$ & $09(18 \%)$ \\
\hline Total & $25(50 \%)$ & $25(50 \%)$ \\
\hline Mean stone size (cm) & $2.8 \pm 0.78$ & $1.9 \pm 0.43$ \\
\hline Mean requirement of analgesia (mg) & $30.2 \pm 5.38$ & $14.8 \pm 9.65$ \\
\hline Mean duration of hospital stay (days) & $2.6 \pm 0.65$ & $1.3 \pm 0.52$ \\
\hline Mean operative time (minutes) & $70.5 \pm 13.24$ & $40.6 \pm 8.86$ \\
\hline
\end{tabular}

Table-I. Characteristics of patients in study group. $(n=50)$

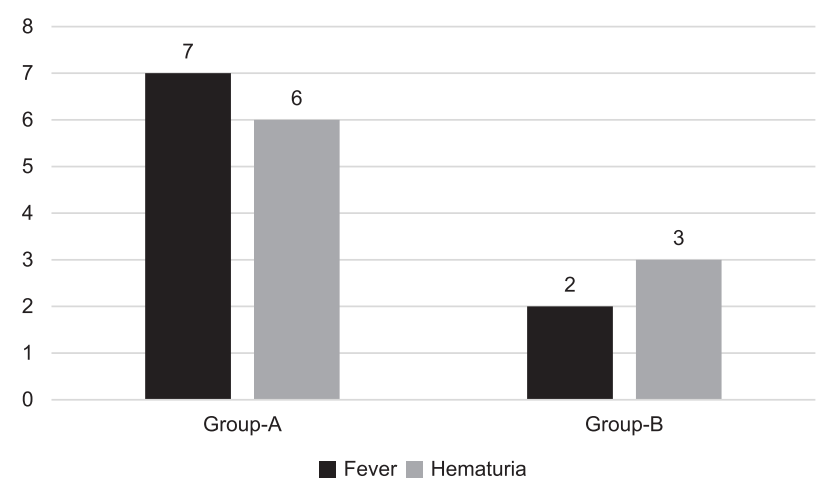

Figure-1. Frequency of common postoperative complications in both groups.

\section{DISCUSSION}

Urinary bladder is the most common site of stone formation among children. Its incidence is slowly declining in endemic areas due to improved life style, nutrition and better healthcare facilities. There are various techniques for vesical stone removal like open vesicolithotomy, percutaneous vesicolithotomy, transurethral laser fragmentation of stone etc. ${ }^{11}$ Now minimally invasive techniques have brought revolution in this field with minimum complications and better outcomes. ${ }^{12}$ Patients undergoing open vesicolithotomy require longer hospital stay, increased analgesia requirement, wound and catheter related complications, postoperative hematuria, urinary tract infection and fever are also common in this technique. Delayed complications include urethral stricture formation. ${ }^{13}$ Transurethral fragmentation of bladder stones using pneumatic intra corporal lithotripsy method is a minimal invasive method which can be used for small size stones but not suitable for large size stones. ${ }^{14}$ Due to prolong operative time and urethral manipulation with instruments it is not a treatment of choice now. ${ }^{15}$

According to a study $7.4 \%$ cases operated with transurethral pneumatic lithotripsy require second surgery for stone fragments removal and prolonged hospital stay is required. ${ }^{16}$ Laser or pneumatic and ultrasonic lithoclast combined method can be used for large urinary bladder stones but this technique is very costly and devices need proper care, highly expert person to use it so it is not suitable for small healthcare centers to afford it. ${ }^{17,18}$ According to a study cystolithoclast method reported minor complications in 10\% cases, postoperative hematuria developed in $05 \%$ cases which was settled after few hours and difficulty in urination was experienced by $04 \%$ cases and urinary retention was experienced by $01 \%$ cases which was relieved by passing urinary catheter. Success rate was $100 \%$ with complete removal of stone with short hospital stay of 10-12 hours. ${ }^{19} \mathrm{~A}$ study conducted by Kamel et al in Egypt on the role of pneumatic and laser techniques in urinary bladder stone removal reported success rate of $97.3 \%$ and complications reported in $8.1 \%$ while prolonged catheterization was required in $5.4 \%$ cases ${ }^{20} \mathrm{~A}$ local study about Transurethral pneumatic lithotripsy role in vesicolithiasis in children reported its excellent outcomes with few minor complications such as fever in 3.5\% cases, dysuria in $10.5 \%$, hematuria in $7 \%$ acute urinary retention was reported in $1.8 \%$ cases. ${ }^{21}$ A previous study conducted in Sheikh Zayed Hospital Rahim Yar khan compared outcomes 
of open vesicolithotomy and percutaneous cystolitholapexy on 30 children. They reported excellent outcomes with minimum complications reported as fever in 08\% cases and hematuria in $12 \%$ cases. $^{22}$

Akmal et al stated that stone clearance rate was $100 \%$ after percutaneous cystolithotripsy with few minor postoperative complications noted such as suprapubic urinary leakage, hematuria, prevesical extravasation of urine and postoperative urinary tract infection. ${ }^{23}$ Ali et al studied outcomes of open vesicolithotomy for large bladder stones with mean stone size of $38.4 \pm 4.2 \mathrm{~mm}$, average hospital stay was $5 \pm 0.6$ days and postoperative complications were reported in $6.9 \%$ cases. ${ }^{24}$ In our study mean hospital duration was 2-3 days among the patients undergoing open vesicolithotomy and 1-2 days duration among those undergoing percutaneous cystolitholapexy. Mean stone size was $2.8 \pm 0.78 \mathrm{~cm}$ and $1.9 \pm$ $0.43 \mathrm{~cm}$. Further studies are required to know outcomes of percutaneous cystolitholapexy among adults as well with larger stone size. In this study sample size was not large. There should be more studies on large sample size and among those having recurrent stones of urinary bladder.

\section{CONCLUSION}

Percutaneous cystolitholapexy is a minimal invasive procedure suitable among children with high success rate and minimum complications like post-operative fever, hematuria, urinary leakage and pain.

\section{Copyright(C) 16 Apr, 2021.}

\section{REFERENCES}

1. Hasan O, Ellis A, Powers R, Vidal P. Vesical megalithiasis. Urology case reports. 2019 Mar; 23:41. https://dx.doi.org/10.1016\%2Fj.eucr.2018.11.012.

2. Bimandama MA, Kurniawaty E. Benign Prostatic Hyperplasia dengan Retensi Urin dan Vesicolithiasis. Jurnal Agromedicine. 2018 Dec 22; 5(02):655-61.

3. Teferi GT, Kifle AT. Management of urolithiasis at hawassa university referral hospital, Ethiopia: A retrospective, descriptive study. East and Central African Journal of Surgery. 2020 Jun 30; 25(2).
4. Liu Y, Chen Y, Liao B, Luo D, Wang K, Li H, Zeng G. Epidemiology of urolithiasis in Asia. Asian journal of urology. 2018 Oct 1 ; 5(4):205-14. https://doi. org/10.1016/j.ajur.2018.08.007

5. Raheem OA, Khandwala YS, Sur RL, Ghani KR, Denstedt JD. Burden of urolithiasis: Trends in prevalence, treatments, and costs. European urology focus. 2017 Feb 1; 3(1):18-26. https://doi.org/10.1016/j. euf.2017.04.001.

6. Zumstein V, Betschart P, Abt D, Schmid HP, Panje CM, Putora PM. Surgical management of urolithiasis-a systematic analysis of available guidelines. BMC urology. 2018 Dec 1; 18(1):25. https://doi.org/10.1186/ s12894-018-0332-9.

7. Gottlieb M, Long B, Koyfman A. The evaluation and management of urolithiasis in the ED: A review of the literature. The American journal of emergency medicine. 2018 Apr 1; 36(4):699-706. https://doi. org/10.1016/j.ajem.2018.01.003.

8. Jung JH, Park J, Kim WT, Kim HW, Kim HJ, Hong $\mathrm{S}$, Yang $\mathrm{HJ}$, Chung $\mathrm{H}$. The association of benign prostatic hyperplasia with lower urinary tract stones in adult men: $A$ retrospective multicenter study. Asian journal of urology. 2018 Apr 1; 5(2):118-21. https://doi. org/10.1016/j.ajur.2017.06.008.

9. Sakamoto S, Miyazawa K, Yasui T, Iguchi T, Fujita M, Nishimatsu H, Masaki T, Hasegawa T, Hibi H, Arakawa T, Ando R. Chronological changes in epidemiological characteristics of lower urinary tract urolithiasis in Japan. International Journal of Urology. 2019 Jan; 26(1):96-101. https://doi.org/10.1111/iju.13817.

10. Girişgen I, Yüksel S, Karcılı K, Becerir T. Evaluation of the composition of urinary tract stones in children from the Inner Western Anatolian Region in Turkey. Turkish journal of urology. 2020 Mar; 46(2):152. https:// dx.doi.org/10.5152\%2Ftud.2019.19170.

11. Iwasa $S$, Yanaihara $H$, Nishimura $C$, Hayashi T, Asakura $\mathrm{H}$. Association of metabolic status with the presence of urinary tract stones requiring surgical intervention. SN Comprehensive Clinical Medicine. 2021 Jan 25:1-6. https://doi.org/10.1007/s42399-021-00773-y.

12. Dhondup T, Kittanamongkolchai W, Vaughan LE, Mehta RA, Chhina JK, Enders FT, Hickson LJ, Lieske JC, Rule AD. Risk of ESRD and mortality in kidney and bladder stone formers. American Journal of Kidney Diseases. 2018 Dec 1; 72(6):790-7. https://doi.org/10.1053/j. ajkd.2018.06.012. 
13. Deswanto IA, Basukarno A, Birowo $P$, Rasyid N. Management of bladder stones: the move towards non-invasive treatment. Medical Journal of Indonesia. 2017 Aug 18; 26(2):128-33. https://doi.org/10.13181/ mji.v26i2.1602.

14. Kittanamongkolchai W, Vaughan LE, Enders FT, Dhondup T, Mehta RA, Krambeck AE, McCollough CH, Vrtiska TJ, Lieske JC, Rule AD. The changing incidence and presentation of urinary stones over 3 decades. In Mayo Clinic Proceedings 2018 Mar 1 (Vol. 93, No. 3, pp. 291-299). Elsevier. https://doi.org/10.1016/j. mayocp.2017.11.018.

15. Javanmard B, Karkan MF, Razzaghi MR, Ghiasy S, Ranjbar A, Rahavian A. Surgical management of vesical stones in children: $A$ comparison between open cystolithotomy, percutaneous cystolithotomy and transurethral cystolithotripsy with holmium-YAG Laser. Journal of lasers in medical sciences. 2018; 9(3):183. https://dx.doi.org/10.15171\%2Fjlms.2018.33.

16. Patodia M, Sharma K, Sankhwar S, Goel A. Bladder calculus leading to acute renal failure in a girl child: A rare cause. Case Reports. 2017 Feb 9; 2017:bcr2016217250. http://dx.doi.org/10.1136/bcr2016-217250.

17. Kareem DA, Abd EM. Intracorporeal pneumatic lithotripsy for treatment of vesical stone in children. Iraqi Academic Scientific Journal. 2017; 16(1).

18. Soliman NA, Rizvi SA. Endemic bladder calculi in children. Pediatric Nephrology. 2017 Sep; 32(9):148999. https://doi.org/10.1007/s00467-016-3492-4.
19. Okada T, Taguchi K, Kato T, Sakamoto S, Ichikawa T, Yasui T. Efficacy of transurethral cystolithotripsy assisted by percutaneous evacuation and the benefit of genetic analysis in a pediatric cystinuria patient with a large bladder stone. Urology Case Reports. 2021 Jan 1; 34:101473. https://doi.org/10.1016/j. eucr.2020.101473.

20. Kamel AA, Shahat AA, Safwat AS, Abdaallah AK. Percutaneous cystolithotripsy in the management of pediatric bladder stone. Journal of Current Medical Research and Practice. 2020 May 1; 5(2):164.

21. Masood A, Khan IZ, Farouk K, Nisar H, ljaz R, Ishtiaq $\mathrm{S}$, Taimur M. Endoscopic management of bladder calculi in paediatric male patients: An experience with 57 patients. Isra Med J. 2019; 11(3):167-70.

22. Hussain I, Qurashi MF, Kanjoo SR, Rashid A. Comparison of percutaneous cystolitholepexy with vesicolithotomy in peadiatric age group for safety and efficacy. The Professional Medical Journal. 2020 Aug 10; 27(08):1742-6. DOI: 10.29309/ TPMJ/2020.27.08.4130.

23. Akmal M, Munir MI, Jafari AA, Subhani GM, Javed $\mathrm{SH}$. Percutaneous cystolithotripsy; Is it safe and successful in all age groups?. Annals of Punjab Medical College (APMC). 2017 Jan 16; 11(1):25-7.

24. Ali L, Hassan A, Orakzai N, Shahzad M, Khan I, Tariq K. Transurethral Resection of Prostate (TURP) and vesicolithotomy for large bladder stone in single session: The third world perspective. Research and reports in urology. 2020; 12:547. https://dx.doi. org/10.2147\%2FRRU.S273375.

\begin{tabular}{|l|l|l|l|}
\hline \multicolumn{3}{|c}{ AUTHORSHIP AND CONTRIBUTION DECLARATION } \\
\hline No. & \multicolumn{1}{|c|}{ Author(s) Full Name } & \multicolumn{1}{c|}{ Contribution to the paper } & Author(s) Signature \\
\hline 1 & Muhammad Shahid Bhatti & $\begin{array}{l}\text { Topic selection, Data } \\
\text { collection, Abstract and } \\
\text { setting. } \\
\text { Data analysis collection. }\end{array}$ \\
\hline 2 & Abdul Qayoom Khuro & Data collection \\
\hline 3
\end{tabular}

